\title{
Low-level trisomy 14 mosaicism in a male newborn with ectrodactyly
}

\author{
M.A. Rodrigues ${ }^{1}$, L.F. Morgade ${ }^{2}$, L.F.A. Dias ${ }^{2}$, R.V. Moreira ${ }^{1}$, P.D. Maia ${ }^{3}$, \\ A.F.H. Sales ${ }^{4}$ and P.D. Ribeiro ${ }^{1}$ \\ ${ }^{1}$ XY Diagnose Laboratório de Biotecnologia, Campos dos Goytacazes, RJ, Brasil \\ ${ }^{2}$ UTI Neonatal Nicola Albano, Campos dos Goytacazes, RJ, Brasil \\ ${ }^{3}$ Universidade Federal do Rio de Janeiro, Rio de Janeiro, RJ, Brasil \\ ${ }^{4}$ Faculdade de Medicina de Campos, Campos dos Goytacazes, RJ, Brasil \\ Corresponding author: M.A. Rodrigues \\ E-mail: mauricioassis@hotmail.com
}

Genet. Mol. Res. 15 (4): gmr15049275

Received September 13, 2016

Accepted October 19, 2016

Published December 2, 2016

DOI http://dx.doi.org/10.4238/gmr15049275

Copyright (C) 2016 The Authors. This is an open-access article distributed under the terms of the Creative Commons Attribution ShareAlike (CC BY-SA) 4.0 License.

\begin{abstract}
Complete trisomy 14 mosaicism is a rare chromosome disorder and was first reported in 1970. We describe a case of a male neonate who presented complete trisomy 14 mosaicism in only $4 \%$ of the cells from peripheral blood. A nineteen-day-old male neonate was born as result of the second pregnancy. The infant was delivered by cesarean section due to gestational hypertension and chronic fetal distress. The length of the term pregnancy was 37 weeks, the birth weight was 3.105 $\mathrm{g}$, the length was $48 \mathrm{~cm}$, and the head circumference was $35.5 \mathrm{~cm}$. The baby remained hospitalized for 19 days in the neonatal intensive care unit due to respiratory distress syndrome and congenital malformations. Physical examination revealed a toned and normal activity, followed by phenotypic changes such as a broader forehead, formation of a cleft
\end{abstract}


palate, hypertelorism, low-set ears, bilateral cryptorchidism, absence of the second toe of the left foot (ectrodactyly), and fusion of third and fourth toes in the right foot (bilateral syndactyly). Cytogenetic analysis was performed on peripheral blood cultures after hospitalization in the neonatal intensive care unit. Analysis of 200 G-banded metaphases showed that $192(96 \%)$ had normal karyotype 46,XY and only $8(4 \%)$ presented trisomy $47, X Y,+14$. It was not possible to perform cytogenetic analysis on the patient's parents. Our patient represents the first case of trisomy 14 disorder to present ectrodactyly.

Key words: Chromosome disorder; Mosaic trisomy 14; Ectrodactyly; Syndactyly

\section{INTRODUCTION}

Homogeneous trisomy 14 is a lethal disease. The mosaic form of this chromosomal abnormality has been described in children and infants and was first reported in 1970 (Fujimoto et al., 1992). Trisomy 14 mosaicism exists not only as complete trisomy but also in the form of partial trisomy through acquisition of supernumerary marker chromosomes (Liehr et al., 2004). Trisomy 14 mosaicism has been reported in tissues such as the skin, as well in amniocentesis, saliva, and umbilical vein blood (Balbeur et al., 2016). Based on previously reported cases on trisomy 14 mosaicism, life expectancy of affected individuals can vary from hours to years (Gersen and Keagle, 2005).

The most common features of this syndrome are growth retardation, psychomotor retardation, dysmorphisms, and abnormal skin pigmentation (Shinawi et al., 2008). Patients usually present dysmorphic craniofacial features such as hypertelorism, micrognathia, ear abnormalities, broad nose, and cleft or highly arched palate (Salas-Labadía et al., 2014). Fetal findings detected during the first trimester include cardiac defects, increased nuchal translucency, dysmorphism, enlarged posterior fossa, and talipes calcaneovarus (Witters et al., 2004). The aim of this study was to report a rare case of a newborn with low-level trisomy 14 mosaicism based on analysis of peripheral blood.

\section{MATERIAL AND METHODS}

\section{Case report}

A nineteen-day-old male neonate was born as result of the second pregnancy to non-consanguineous parents (the first pregnancy resulted in miscarriage during the first trimester), a 25-year-old mother and a 29-year-old father. Both parents denied alcoholism, smoking, and drug use. The mother had complications during pregnancy, with preterm threat between the third and fourth months, remaining hospitalized for four days due to urinary tract infection and vaginal thrush. The infant was delivered by cesarean section due to gestational hypertension and chronic fetal distress. The length of the term pregnancy was 37 weeks, the birth weight was $3.105 \mathrm{~g}$, the length was $48 \mathrm{~cm}$, and the head circumference was $35.5 \mathrm{~cm}$. The baby remained hospitalized for 19 days in the neonatal intensive care unit due to respiratory distress syndrome and congenital malformations. After hospital discharge, his corresponding

Genetics and Molecular Research 15 (4): gmr15049275 
measurements were: weight of $3.428 \mathrm{~g}$, length of $50 \mathrm{~cm}$, and head circumference of $38.5 \mathrm{~cm}$. In addition, transfontanellar ultrasound examination detected a slight increase in the volume of lateral ventricles. Physical examination revealed a toned and normal activity, followed by phenotypic changes such as a broader forehead, formation of a cleft palate, hypertelorism, low-set ears, bilateral cryptorchidism, absence of the second toe of the left foot (ectrodactyly), and fusion of third and fourth toes in the right foot (bilateral syndactyly). The child is currently one year old and healthy.

This study was conducted with approval from the Ethics Committee of Nicola Albano Neonatal Intensive Care Unit. Informed written consent was obtained from the patient's parents before enrollment in the study in compliance with the ethical guidelines of the Declaration of Helsinki amended in 2008.

\section{Cytogenetic study}

Cytogenetic analysis was performed on peripheral blood cultures after hospitalization in the neonatal intensive care unit. Analysis of $200 \mathrm{G}$-banded metaphases showed that 192 (96\%) had normal karyotype 46,XY and only 8 (4\%) presented trisomy 47,XY,+14 (Figure 1). It was not possible to perform cytogenetic analysis on the patient's parents.

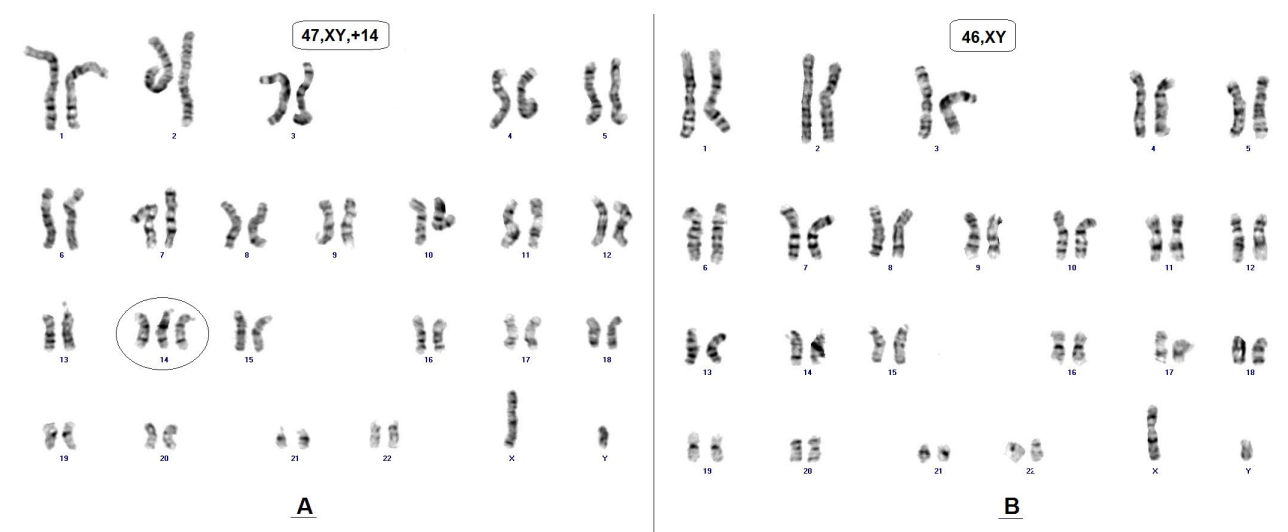

Figure 1. G-banded karyotype of the neonate. A. 47,XY,+14; B. 46,XY.

\section{DISCUSSION}

We report the case of a male neonate who presented complete trisomy 14 mosaicism in only $4 \%$ of the cells from peripheral blood, the same rate previously reported by Fujimoto et al. (1992) in a female patient. We compared the clinical manifestations of our case with 21 other cases of complete trisomy 14 mosaicism that have been described to date (Table 1). The publication dates of included studies ranged from 1975 to 2016. Most of the patients were female $(14 / 21,67 \%)$. Maternal age was reported in 18 of 21 cases and ranged from 18 to 43 years (mean $29.10 \pm 6.77$ ). However, maternal age was below 30 years of age in the majority of the cases. The patients' ages varied between 1 day and 15 years old.

Genetics and Molecular Research 15 (4): gmr15049275 
Table 1. Features of complete trisomy 14 mosaicism cases.

\begin{tabular}{|c|c|c|}
\hline Characteristics & This case & Previous reports* \\
\hline \multicolumn{3}{|l|}{ Cytogenetic study } \\
\hline$\%$ extra chromosome 14 in blood & $4 \%$ & $4 \%-70 \%(20,60 \pm 15.89)$ \\
\hline Gender & Male & $\begin{array}{l}14 \text { Females } \\
7 \text { Males }\end{array}$ \\
\hline \multicolumn{3}{|l|}{ Neurological/development } \\
\hline Growth retardation & + & $20 / 21$ \\
\hline Body asymmetry & - & $11 / 21$ \\
\hline Hypotonia & - & $6 / 21$ \\
\hline \multicolumn{3}{|l|}{ Craniofacial } \\
\hline Microcephaly & - & $5 / 21$ \\
\hline Proeminent/Broad forehead & + & $10 / 21$ \\
\hline Hypertelorism & + & $8 / 21$ \\
\hline Abnormal palpebral fissures & - & $11 / 21$ \\
\hline Micro/Retrognathia & - & $14 / 21$ \\
\hline Broad nose & + & $14 / 21$ \\
\hline Cleft palate or lip & - & $3 / 21$ \\
\hline High arch palate & - & $6 / 21$ \\
\hline Low set ears & + & $7 / 21$ \\
\hline Epicanthal folds & - & $4 / 21$ \\
\hline \multicolumn{3}{|l|}{ Neck/Genitalia } \\
\hline Micropenis & - & $4 / 7$ \\
\hline Cryptorchidia & + & $4 / 7$ \\
\hline Short neck & - & $10 / 21$ \\
\hline \multicolumn{3}{|l|}{ Cardiac/Hepatic } \\
\hline Heart defects & + & $16 / 21$ \\
\hline Hepatic defects & - & $2 / 21$ \\
\hline \multicolumn{3}{|l|}{ Extremities/Skin } \\
\hline Abnormal pigmentation & - & $9 / 21$ \\
\hline Syndactyly & + & $2 / 21$ \\
\hline Clinodactyly & - & $5 / 21$ \\
\hline Ectrodactyly & + & NR \\
\hline Other malformations of the hands/feet & - & $12 / 21$ \\
\hline
\end{tabular}

*Rethoré et al. (1975); Martin et al. (1977); Johnson et al. (1979); Dallapiccola et al. (1984); Petersen et al. (1986); Kaplan et al. (1986); Lipson (1987); Vachvanichsanong et al. (1991); Fujimoto et al. (1992); Iglesias et al. (1997); Sepulveda et al. (1998); Lynch et al. (2004); Kunst and Gillbe (2005); Merritt and Natarajan (2007); McGaughran et al. (2009); Choi et al. (2012); Hur and Hwang (2012); Eventov-Friedman et al. (2015); Suzumori et al. (2015); Balbeur et al. (2016). NR: not recorded.

The frequency of mosaicism in fibroblasts ranged from 0.5 to $16 \%$ (mean $5.8 \pm 4.8$ ), while that of peripheral blood ranged from 4 to $70 \%$ (mean $20.70 \pm 16.29$ ). Out of 21 reports, $9(43 \%)$ analyzed both skin fibroblasts and peripheral blood (Rethoré et al., 1975; Martin et al., 1977; Petersen et al., 1986; Lipson, 1987; Fujimoto et al., 1992; Iglesias et al., 1997; Lynch et al., 2004; Merritt and Natarajan, 2007; McGaughran et al., 2009), whereas more than two tissues were studied in 2 cases (9.5\%) (Suzumori et al., 2015; Balbeur et al., 2016).

Growth retardation was the most frequently reported feature, being found in $95 \%$ $(20 / 21)$ of the patients. This is followed by heart defect $(16 / 21,76 \%)$ and micro/retrognathia and broad nose, both of which were found in $67 \%(14 / 21)$ of all cases. The less frequently observed characteristics were hepatic defects and syndactyly, which were found in only $9.5 \%$ $(2 / 21)$ of the cases. Additional characteristics presented by our patient were frequently reported in other studies found in literature (von Sneidern and Lacassie, 2008; Rodovalho-Doriqui et al., 2013; Zou et al., 2016). Out of the 21 studies, three reported mortalities in females aged 1 to 36 days (Fujimoto et al., 1992; Sepulveda et al., 1998; Suzumori et al., 2015). Suzumori et al. (2015) and Sepulveda et al. (1998) reported twin pregnancy discordant for trisomy 14 
mosaicism in monochorionic and dichorionic twins, respectively.

One limitation of the current study is that cytogenetic analyses were not conducted on the patient's parents, who refused due to emotional reasons. Moreover, analysis on other tissue types was not performed because the doctor did not find it necessary for diagnosis. However, most reports $(11 / 21,52 \%)$ studied more than one tissue type. Balbeur et al. (2016) reported a patient with maternal uniparental disomy of chromosome 14 and discrepant mosaicism in blood, urine, saliva, and skin. Suzumori et al. (2015) reported a maternal uniparental disomy of chromosome 14 and detected trisomy 14 in amniocentesis and umbilical vein blood tissue. In both cases, the phenotype was consistent with previous reports of trisomy 14 mosaicism.

Abnormal skin pigmentation was not reported in our patient but was observed in $43 \%$ (9/21) of the other cases. According to Fujimoto et al. (1992), abnormal skin pigmentation may represent a sign of mosaicism. Data from the present study seem to contradict the correlation between abnormal pigmentation and trisomy chromosome 14 mosaicism in fibroblasts. Lynch et al. (2004) reported the only case that did not present trisomy 14 in skin fibroblasts; however, the patient showed abnormal skin pigmentation. The authors did not reveal the number of cells analyzed, and a low score may be not able to identify a chromosomal mosaicism. On the other hand, Petersen et al. (1986) and Merritt and Natarajan (2007) described mosaicism in fibroblasts, and their patients did not exhibit abnormal pigmentation of the skin. Petersen et al. (1986) reported a patient with $16 \%$ mosaicism in fibroblasts, the highest rate reported out of all studies included in this research. A larger number of cases must be studied in order to reliably establish a correlation between the frequency of mosaicism and clinical features.

Merritt and Natarajan (2007) described the first case of a child with mosaic trisomy 14 but without evidence of neurodevelopmental delay at 6 years of age. This effect may be associated with the smaller percentage of mosaic cells or lack of tissue involvement, although cytogenetic analyses on tissues derived from the nervous system were not performed (Merritt and Natarajan, 2007).

Our patient presented fusion of third and fourth toes in the right foot (bilateral syndactyly) and absence of the second toe of the left foot (ectrodactyly), a characteristic that has not been previously reported for trisomy 14 mosaicism. Syndactyly was previously described only by Merritt and Natarajan (2007) and Kaplan et al. (1986), while clinodactyly was reported in five patients (Martin et al., 1977; Lynch et al., 2004; Merritt and Natarajan, 2007; Choi et al., 2012; Balbeur et al., 2016).

Notably, 71\% (15/21) of the cases described at least one alteration in the extremities of the body, such as overlapping fingers, hypoplasia, fixed contractures of the hands, and elongated fingers. These data show that alterations in the extremities appear to be outstanding clinical manifestations of trisomy 14 mosaicism. According to Fujimoto et al. (1992), the clinical manifestations of trisomy chromosome 14 mosaicism can be quite varied, and most features are also observed in other chromosomal abnormalities. However, there is overall uncertainty regarding the correlation between the severity of the clinical phenotype and the proportion of the trisomic cell line (Fujimoto et al., 1992; von Sneidern and Lacassie, 2008).

In conclusion, our study revealed only $4 \%$ complete trisomy 14 mosaicism in the peripheral blood of our patient. This is the lowest rate ever reported for complete trisomy 14 mosaicism and the same as that previously reported by Fujimoto et al. (1992). Moreover, our patient represents the first case of trisomy 14 disorder to present ectrodactyly. Most of the clinical manifestations described for this syndrome were also found in other chromosomal abnormalities; however, alterations in the extremities of the body appear to be notable features

Genetics and Molecular Research 15 (4): gmr15049275 
for trisomy 14 mosaicism. A greater number of case reports are required to establish a more reliable correlation between the clinical features and the cytogenetic findings.

\section{Conflicts of interest}

The authors declare no conflict of interest.

\section{ACKNOWLEDGMENTS}

Research supported by XY Diagnose Laboratório de Biotecnologia. We are grateful to the patient's parents for their collaboration.

\section{REFERENCES}

Balbeur S, Grisart B, Parmentier B, Sartenaer D, et al. (2016). Trisomy rescue mechanism: the case of concomitant mosaic trisomy 14 and maternal uniparental disomy 14 in a 15-year-old girl. Clin. Case. Rep. 2: 265-271.

Choi JH, Choi YJ and Kim SY (2012). Congenital ocular anomaly in an infant with trisomy 14 mosaicism. Korean J. Ophthalmol. 26: 316-318. http://dx.doi.org/10.3341/kjo.2012.26.4.316

Dallapiccola B, Ferranti G, Giannotti A, Novelli G, et al. (1984). A live infant with trisomy 14 mosaicism and nuclear abnormalities of the neutrophils. J. Med. Genet. 21: 467-470. http://dx.doi.org/10.1136/jmg.21.6.467

Eventov-Friedman S, Frumkin A, Bar-Oz B and Raas-Rothschild A (2015). Mosaic Trisomy 14 in a Newborn with Multiple Malformations: When Chromosomal Microarray is a Clue to Diagnosis. Isr. Med. Assoc. J. 17: 459-460.

Fujimoto A, Allanson J, Crowe CA, Lipson MH, et al. (1992). Natural history of mosaic trisomy 14 syndrome. Am. J. Med. Genet. 44: 189-196. http://dx.doi.org/10.1002/ajmg.1320440214

Gersen SL and Keagle MB (2005). The Principles of Clinical Cytogenetics. 2nd edition. Humana Press, New Jersey.

Hur YJ and Hwang T (2012). Complete trisomy 14 mosaicism: first live-born case in Korea. Korean J. Pediatr. 55: 393 396. http://dx.doi.org/10.3345/kjp.2012.55.10.393

Iglesias A, McCurdy LD, Glass IA, Cotter PD, et al. (1997). Mosaic trisomy 14 with hepatic involvement. Ann. Genet. 40: $104-108$.

Johnson VP, Aceto T, Jr. and Likness C (1979). Trisomy 14 mosaicism: case report and review. Am. J. Med. Genet. 3: 331-339. http://dx.doi.org/10.1002/ajmg.1320030404

Kaplan LC, Wayne A, Crowell S and Latt SA (1986). Trisomy 14 mosaicism in a liveborn male: clinical report and review of the literature. Am. J. Med. Genet. 23: 925-930. http://dx.doi.org/10.1002/ajmg.1320230407

Kunst $\mathrm{G}$ and Gillbe C (2005). General anesthesia for cardiac catheterization in a child with trisomy 14 mosaicism. Anesth. Analg. 100: 1860. http://dx.doi.org/10.1213/01.ANE.0000156687.85500.4B

Liehr T, Claussen U and Starke H (2004). Small supernumerary marker chromosomes (sSMC) in humans. Cytogenet. Genome Res. 107: 55-67.http://dx.doi.org/10.1159/000079572

Lipson MH (1987). Trisomy 14 mosaicism syndrome. Am. J. Med. Genet. 26: 541-544. http://dx.doi.org/10.1002/ ajmg. 1320260305

Lynch MF, Fernandes CJ, Shaffer LG and Potocki L (2004). Trisomy 14 mosaicism: a case report and review of the literature. J. Perinatol. 24: 121-123. http://dx.doi.org/10.1038/sj.jp.7211048

Martin AO, Ford MM, Khalil NT, Turk KB, et al. (1977). 46,XX/47XX, + 14 mosaicism in a liveborn infant. J. Med. Genet. 14: 214-218.http://dx.doi.org/10.1136/jmg.14.3.214

McGaughran J, Stevens R, Blond A and Perry C (2009). Nasal encephalocele in a child with mosaic trisomy 14. Clin. Dysmorphol. 18: 164-165.http://dx.doi.org/10.1097/MCD.0b013e32832921b9

Merritt TA and Natarajan G (2007). Trisomy 14 Mosaicism: a case without evidence of neurodevelopmental delay and a review of the literature. Am. J. Perinatol. 24: 563-566. http://dx.doi.org/10.1055/s-2007-986691

Petersen MB, Vejerslev LO and Beck B (1986). Trisomy 14 mosaicism in a 2 year old girl. J. Med. Genet. 23: 86-88. http:// dx.doi.org/10.1136/jmg.23.1.86

Rethoré MO, Couturier J, Carpentier S, Ferrand J, et al. (1975). [Mosaic 14 trisomy in a female child with multiple abnormalities]. Ann. Genet. 18: 71-74.

Rodovalho-Doriqui MJ, Freitas PL, Pinho JD, Cavalli LR, et al. (2013). 3p partial trisomy and 13q partial monosomy with congenital malformations and psychomotor developmental delay. Genet. Mol. Res. 12: 2562-2566. http://dx.doi. org/10.4238/2013.July.24.7

Genetics and Molecular Research 15 (4): gmr15049275 
Salas-Labadía C, Lieberman E, Cruz-Alcívar R, Navarrete-Meneses P, et al. (2014). Partial and complete trisomy 14 mosaicism: clinical follow-up, cytogenetic and molecular analysis. Mol. Cytogenet. 25; 7: 65.

Sepulveda W, Monckeberg MJ and Be C (1998). Twin pregnancy discordant for trisomy 14 mosaicism: prenatal sonographic findings. Prenat. Diagn. 18: 481-484. http://dx.doi.org/10.1002/(SICI)1097-0223(199805)18:5<481::AIDPD274>3.0.CO;2-Z

Shinawi M, Shao L, Jeng LJB, Shaw CA, et al. (2008). Low-level mosaicism of trisomy 14: phenotypic and molecular characterization. Am. J. Med. Genet. A. 146A: 1395-1405. http://dx.doi.org/10.1002/ajmg.a.32287

Suzumori N, Kagami M, Kumagai K, Goto S, et al. (2015). Clinical and molecular findings in a patient with $46, \mathrm{XX} / 47, \mathrm{XX},+14$ mosaicism caused by postzygotic duplication of a paternally derived chromosome 14 . Am. J. Med. Genet. A. 167A: 2474-2477. http://dx.doi.org/10.1002/ajmg.a.37194

Vachvanichsanong P, Jinorose U and Sangnuachua P (1991). Trisomy 14 mosaicism in a 5-year-old boy. Am. J. Med. Genet. 40: 80-83. http://dx.doi.org/10.1002/ajmg.1320400116

von Sneidern E and Lacassie Y (2008). Is trisomy 14 mosaic a clinically recognizable syndrome? - case report and review. Am. J. Med. Genet. A. 146A: 1609-1613.http://dx.doi.org/10.1002/ajmg.a.32334

Witters I, Moerman P and Fryns JP (2004). First-trimester scan in trisomy 14 mosaicism. Prenat. Diagn. 24: 573-574. http://dx.doi.org/10.1002/pd.823

Zou PS, Li HF, Chen LS, Ma M, et al. (2016). A rare case of trisomy 11q23.3-11q25 and trisomy 22q11.1-22q11.21. Genet. Mol. Res. 15: gmr.15028140. 